\title{
Comprehensive seismic risk assessment map of South Korea developed using seismic, geotechnical, and social vulnerability indicators
}

Seonyoung Lee

Kangwon National University

Seokhoon Oh ( $\sim$ gimul@kangwon.ac.kr)

Kangwon National University https://orcid.org/0000-0002-3670-3336

\section{Research Article}

Keywords:

Posted Date: June 15th, 2021

DOl: https://doi.org/10.21203/rs.3.rs-289104/v1

License: (c) (i) This work is licensed under a Creative Commons Attribution 4.0 International License.

Read Full License 


\section{Abstract}

At present, because it is not possible to predict earthquakes, disaster preparedness is vital for the reduction of damages. The awareness about earthquakes has substantially increased after the occurrence of two >M L 5 events in 2016 and 2017 in South Korea. This study presents the seismic risk assessment conducted for the entire country of South Korea. This assessment was performed using seismic, geotechnical, and social vulnerability indicators. The seismic vulnerability indicator was estimated using a probabilistic seismic hazard and fault-line density map that are directly related to the occurrence of earthquakes. The geotechnical vulnerability indicator was derived using bedrock depth data and extrapolation of digital elevation model data through geostatistical techniques. The seismic and geotechnical indicators were integrated based on the bedrock depth distribution. The social vulnerability indicator considered the distribution of relevant parameters such as vulnerable people, old houses, and road information. These statistical data without spatial continuity were incorporated into a map using principal component analysis. A five-grade classification of risks presented by the seismic and geotechnical vulnerability map and the social vulnerability index map was developed to facilitate simultaneous assessment. A risk matrix was applied to the two maps to produce a comprehensive seismic risk assessment map of South Korea, in which the southeastern and northwestern regions of South Korea present a high seismic risk. The results of this study will serve toward seismic risk management and minimize seismic disaster damages in South Korea.

\section{Introduction}

The Korean Peninsula is located within the Eurasian Plate and experiences less seismic activity than countries located at plate boundaries, such as those in the Circum-Pacific seismic zone. Therefore, it is practically impossible to make spatiotemporal predictions of the occurrence of earthquakes (Lee 1988; Lee 1998; Shin et al. 2016) in South Korea. In-depth research is required to propose effective countermeasures against earthquake damage. South Korea is widely perceived as a relatively safe region with low seismic risk and, therefore, limited research has been conducted on related topics (Han et al. 2013). However, the $2016 M_{L} 5.8$ Gyeongju earthquake and the $2017 M_{L} 5.4$ Pohang earthquake resulted in substantial human and material damages (MPSS 2017; MOIS 2018). After these recent moderate earthquake events, the interest in seismic risk research to reduce earthquake damage has markedly increased in South Korea.

Seismic risk is evaluated by taking into account indicators that reflect aspects such as earthquake, economy, and society using geographic information systems (GIS). The Federal Emergency Management Agency (FEMA) of the United States evaluates economic and social losses caused by seismic hazards in terms of direct and indirect damages using the Hazus earthquake model developed by the National Institute of Building Sciences (NIBS). Hazus is a GIS-based system that is used as a decision-making tool to prepare against disasters in advance (FEMA 2012). Japan operates the disaster information system (DIS) to display a variety of information, such as earthquake magnitude, geology, topography, buildings, and population, on a GIS-based platform to predict the extent of earthquake damage and execute the 
initial response system (CAO 2015). Frigerio et al. (2016) created and integrated the probabilistic seismic hazard map and the social vulnerability index (SVI) map of Italy, considering an earthquake return period of 475 years, to evaluate seismic risk.

For similar purposes, studies were conducted on ground vulnerability to earthquake damage. Grasso and Maugeri (2009) used synthetic accelerograms of the ground surface and bedrock depth to analyze ground motion and site effects to evaluate physical vulnerabilities, such as landslides and liquefaction, caused by earthquakes in the Mediterranean region. De Magistris et al. (2014) analyzed two case studies in Italy to study seismic response and seismic microzonation in urban areas. Their findings suggest that in the event of an earthquake, the damage could be regionally different depending on soil conditions, and details of the map could be greatly improved when bedrock depth was used as a soil classification parameter. Although the above examples show that bedrock depth is important in evaluating geotechnical vulnerability, these studies were limited to local scales as they considered seismic response analysis.

Studies on earthquake vulnerability evaluation using bedrock depth based on spatial analysis have been conducted. Mohanty et al. (2007) considered five parameters, peak ground acceleration (PGA), soil, geology, groundwater fluctuation, and bedrock depth, and performed a seismic microzonation based on an analytic hierarchy process (AHP) and GIS centered on Delhi, India. Kim and Chung (2016) constructed a GIS-based earthquake hazard assessment system using geotechnical spatial grid information. Changes in bedrock depth were analyzed to identify spatial changes in ground conditions that cause earthquake hazards in the study area. However, these studies focused on ground characteristics and did not include social vulnerability in the analysis.

This study creates a seismic risk map of South Korea through a comprehensive evaluation that considers seismic, geotechnical, and social vulnerabilities. Because bedrock depth is closely related to earthquake damage, it was selected as a representative factor of geotechnical vulnerability. Simple kriging with local varying means (SK-LVM) was applied to calculate high-resolution bedrock depth information based on borehole data. Because the social vulnerability indicator is based on statistical data, weights were calculated using multivariate statistical analysis, and the weighted values were summed. Finally, the seismic and geotechnical vulnerability and SVI maps were graded at five levels and integrated based on a risk matrix. We aimed to create a seismic risk map covering the entire country through this approach to facilitate intuitive interpretation.

\section{Study Area}

The Korean Peninsula is located between $124-132^{\circ} \mathrm{E}$ and $33-44^{\circ} \mathrm{N}$, covering an area of $223,404 \mathrm{~km}^{2}$. The territory is located in a region that connects the Eurasian continent to the Pacific Ocean; it borders China and Russia in the north and is separated from Japan by the Korea Strait (NGII 2017). South Korea has a population of 47.99 million and a population density of 486 people/ $\mathrm{km}^{2}$, which is one of the 
highest in the world except for city states (NGII 2018). Therefore, in the event of a natural disaster, highly destructive and complex losses may occur. Fig. 1 shows a map of the study area.

Instrumental earthquake observation began in South Korea in 1978. Since the late 1980s, the seismic observation network has been modernized and the performance of the seismic analysis system has improved, leading to a higher frequency of the detection of earthquakes with $M_{L}$ 2.0-3.0 magnitudes. Since 2000, the total number of earthquake occurrences has stabilized (KOSIS 2020). However, on September $12,2016, M_{L} 5.1$ and $M_{L} 5.8$ earthquakes occurred consecutively in Gyeongju, a city located in southeast South Korea. Although the actual damage was not large, considering the seismic magnitude, ground motion was felt not only in the area around the epicenter but also in many areas in the southeastern region of the country. After the earthquake in Gyeongju, earthquake activity within South Korea has increased (KMA 2017). On November 15, 2017, approximately a year after the Gyeongju event, an $M_{L} 5.4$ earthquake occurred in Pohang. It was the second largest earthquake observed after seismological observation stations were established in South Korea. Thereafter, the number of aftershocks experienced in South Korea increased significantly. After the Pohang earthquake, until May 31,2018 , aftershocks of $M_{L} 2.0$ or higher were observed 100 times, with total number of earthquakes being 615, including microearthquakes (KMA 2018). These numbers indicate the possibility of the occurrence of a larger-scale earthquake in South Korea that can cause severe damages.

\section{Datasets For Vulnerability Indexes}

Seismic, geotechnical, and social vulnerabilities were considered while analyzing seismic risk in South Korea. Table 1 summarizes the variables and data sources used in the study. The seismic vulnerability indicator was computed using the results of the probabilistic seismic hazard analysis (PSHA) for a return period of 475 years and information on fault-line locations. The geotechnical vulnerability indicator was derived using bedrock depth, which is an important variable for evaluating ground vulnerability (Mohanty et al. 2007). The social vulnerability indicator was computed using information on vulnerable people, old houses, and road information (Cutter et al. 2003).

\subsection{Seismic vulnerability indicator}

Seismic vulnerability is assessed for the seismic design of buildings and should be considered for analyzing seismic risks. In this study, the PSHA and fault-line density map were used as indicators.

\subsubsection{Probabilistic seismic hazard analysis}

PSHA is a method that quantifies the probability of exceeding various ground motion levels at a specific site due to earthquakes using earthquake records, attenuation relationships, and other parameters (CRPC 2017). The national seismic hazard map published by the NEMA in 2013 shows the probabilities of occurrence of earthquakes exceeding $10 \%$ for the past 50 years. The data from this map were converted to the raster format using ordinary kriging (OK) and used for the PSHA (Lee and Oh 2019). 
Figure 2 shows the PSHA constructed using spatial information. Blue and red indicate moderate and high ground accelerations, respectively. Because PSHA is based on earthquake records, the distribution of earthquake occurrence is in an L-shaped region in South Korea. In addition, red areas with higher ground acceleration will experience more collapse and destruction of buildings and, hence, require improved seismic design (NEMA 2013). These red areas have high seismic vulnerability.

\subsubsection{Fault-line density map}

As earthquakes are caused by sudden displacement or rupture of faults, information on faults is closely related to seismic activities. As most earthquakes are known to occur along active faults, we utilized an active fault map. However, detailed information on active faults and fault displacement in South Korea is not sufficiently available (NEMA 2012; Kyung et al. 2016). In addition, the range of fault rupture associated with the extent of earthquake damage is highly dependent on fault length. We used a faultline density map, which was constructed by utilizing the active fault map and lineament class map presented by NEMA, and the fault line length was acquired through the 1:1,000,000 geological map of the Korea Institute of Geoscience and Mineral Resources (KIGAM) (Table 1). This approach takes into account the damage from earthquakes in the fault location and its surrounding areas.

Figure 3 shows the overall schematic diagram for the construction of the fault-line density map. First, fault length information was applied with weights to calculate the active fault-line density (Fig. 3a). Next, the fault-line density was calculated using the lineament class map to assign different weights to each class (Fig. 3b). Because the two fault-line densities represent different physical quantities, they were normalized using Z-score transformation, and then, the weighted values are summed. As the active fault map is an important variable, more weight was assigned to this map, and then, the two were integrated at a ratio of 7:3. As a result, a fault-line density map (Fig. 3c) was created. The distribution of Fig. $3 a$ and $b$ is spatially reflected in Fig. 3c. The red-colored region in the map represents a higher fault-line density. The minimum value represented in blue is $15 \mathrm{~km}$ or more away from the fault line, indicating an area with a low fault-line density value, i.e., with low seismic vulnerability. Comparatively higher fault-line density values were observed in the Yangsan fault zone, Chugaryeong fault zone, and Ogcheon folded belt, which are areas that are speculated to have active faults, and are represented as high classes in the lineament class diagram. Overall, the fault-lines show a northeast orientation, and high seismic vulnerability from faults is increases further in the order southeastern < northwestern < southwestern regions of South Korea.

\subsection{Geotechnical vulnerability indicator}

Bedrock depth is directly related to the respective site and is recognized as an essential parameter in terms of geotechnical and seismic engineering. Therefore, it was selected as a representative indicator of geotechnical vulnerability (Toprak and Holzer 2003; Sun et al. 2008). When a soil layer is thick or bedrock deep, ground motion is easily amplified, and thus, a relatively large damage can be predicted (Sun and Kim 2017). In this study, the depth to the weathered rock from the surface was considered as the bedrock depth. Borehole data from the Korea Institute of Civil Engineering and Building Technology (KICT) were 
used. Although 348 borehole observations were used, elevations of the borehole locations were not considered in the bedrock depth information. Furthermore, the number of data points was not proportionate to the vast area considered for the study (Fig. 4a). Therefore, we used digital elevation model (DEM) data with 90-m intervals, which were correlated with bedrock depth to supplement the borehole data (Fig. 4b). Bedrock depth and DEM data are expected to have a strong correlation with each other, as thicker soil layers develop in plains rather than mountainous terrain with high altitude, and the products of weathering and erosion tend to migrate and deposit in the lower regions. Data processing information is described in section 4.1.1.

\subsection{Social vulnerability indicator}

Socioeconomic factors also have an important effect on the degree of damage caused by natural disasters (Westgate and O'Keefe 1976). Here, socioeconomic factors represent social vulnerability. Studies were conducted to evaluate social vulnerability at the national and regional levels using a number of related indicators and sub-variables to develop social vulnerability indices (Felsenstein and Lichter 2014). Among various factors that were evaluated, it is known that the results are statistically valid even when only a few factors are used to assess social vulnerability (Brooks et al. 2005). Therefore, in this study, based on the social characteristics of South Korea, we chose vulnerable people, old houses, and road information as social vulnerability indicators.

\subsubsection{Vulnerable people}

Vulnerable people refer to those who are vulnerable to disasters, such as children, elderly, and disabled people, according to Article 3, Paragraph 9-3 of the Framework Act on the Management of Disasters and Safety in South Korea. Age-related variables have been widely used in studies on social vulnerability evaluation (Siagian et al. 2014). "People with severe disabilities" refers to those with considerable impairment that significantly limits performance of activities in daily living and social life.

In this study, infants aged 4 years or below, people aged 65 years or older, and people with severe disabilities, all of whom would need external aid or are expected to experience a substantial decrease in coping abilities in the event of an earthquake, were selected as variables. For the data on infants and older people, the age and gender demographic data updated in August 2018 from Statistics Korea's population census were used. Data on the number of persons with disabilities registered in the Ministry of Health and Welfare in 2018 were used. Figure 5a shows the spatial distribution of these vulnerable people.

\subsubsection{Old houses: 30 years or older}

In South Korea, seismic design was regulated by law in 1988 for buildings with six stories or higher. Buildings built before 1988 have been constructed with no seismic design consideration (Han 2011) and are likely to be exposed to the risk of collapse in the event of an earthquake. Since then, related laws have been amended several times, and according to the current Building Act, seismic design standards have 
been expanded to buildings with two or more stories and a total area of $200 \mathrm{~m}^{2}$ or more. However, in reality, during the 2016 Gyeongju earthquake, low-rise buildings without seismic design were damaged, indicating that these buildings were very vulnerable to earthquakes (Related Ministries, Korea 2016). Of the 4.5 million buildings in December 2015, only 6.9\% followed seismic design guidelines (Kim 2017). After the Pohang earthquake in 2017, the government has become stricter in implementing seismic retrofitting and safety management of public facilities. However, for private facilities, such as housing, seismic retrofitting is only performed voluntarily (Related Ministries, Korea 2018). In this study, we used Statistics Korea's 2017 data to classify houses over 30 years old as the distinguishing criterion to classify vulnerability to earthquakes. Figure $5 \mathrm{~b}$ shows the spatial distribution of old houses.

\subsubsection{Road density by administrative district}

The destruction of social infrastructure, such as sewerage, transportation, telecommunications, and electric power, due to natural disasters causes direct and indirect losses, resulting in financial burdens on small enterprises, organizations, and societies (Cutter et al. 2003). As South Korea has advanced industrialization, various social infrastructures are interconnected, and the destruction of only few facilities can affect others, leading to great economic losses (Ha 2012). We considered roads as an indicator of social infrastructure. This choice was appropriate as data collection is easy and many other infrastructure facilities, such as power distribution, communications systems, water pipes and sewage, and gas networks, were constructed along roads. The standard node link data from the Ministry of Land, Infrastructure and Transport as of January 2019 were used as the database. As the data are for the entire country, information on national expressways, urban expressways, and general national roads was used. Vector-type data were used to calculate the road density of each administrative district. Figure $5 \mathrm{c}$ shows the spatial distribution of road density.

\section{Methods}

To perform the overall seismic risk analysis, each indicator was selected to represent the respective aspects of seismic, geotechnical, and social vulnerabilities (Table 1). Seismic and geotechnical vulnerability indicators were mapped using geostatistics and GIS techniques. Multivariate statistical techniques were applied to calculate the SVI, and the result was produced as a map. These two sets of results were graded and integrated to produce the risk matrix, and a seismic risk map was generated.

\subsection{Mapping of geotechnical vulnerability with seismic vulnerability}

\subsubsection{Application of geostatistics to bedrock depth}

As the borehole data were limited, interpolation of bedrock depth through correlation techniques can reduce the prediction uncertainty of bedrock depth at points where there are no boreholes.

We performed correlation analysis between bedrock depth as the primary data and DEM as the secondary data. Figure 6a shows a negative correlation between them, with a coefficient of determination of 0.13 . 
Therefore, bedrock depth was converted to bedrock elevation to increase the correlation. The coefficient of determination between bedrock elevation and the DEM was close to 1, indicating a remarkably high correlation. However, the data tended to be concentrated in the lowlands, resulting in a scattered data distribution (Fig. 6a). In addition, if we extracted only points of elevation with $40 \mathrm{~m}$ or less from DEM, the coefficient of determination decreased to 0.88 (Fig. 6b). Hence, the correlation between DEM and bed rock depth is very high for highlands, but at points below elevation of $40 \mathrm{~m}$, the correlation is significantly low. To improve the accuracy of the relationship between the two datasets with low elevation, the SK-LVM multivariate kriging technique was applied.

SK-LVM is simple and practical and has the advantage of reducing the smoothing effect and increasing the resolution (Goovaerts 2000). Figure 7a describes the methodology of SK-LVM. Regression analysis of primary and secondary data calculates the expected value at each location of the secondary data and takes into account the distribution of primary data. The residual, which is the difference between the primary data and the expected value at that point, is calculated. Then, an estimate is obtained by adding the calculated expected value to the result by applying simple kriging (SK) to this residual (Goovaerts 2000). Figure $7 \mathrm{~b}$ shows the process of estimating bedrock elevation by adding the local varying means (LVM) of bedrock elevation achieved through regression analysis in this study to the result of applying SK to the residual.

Figure 8a shows the result of converting the estimated bedrock elevation to bedrock depth. Green indicates a low depth, while red indicates a high depth. Overall, bedrock depth along the national rivers, corresponding to large rivers in South Korea, was high. Thick, alluvial soil layers, widely distributed in the downstream regions, were predicted. Inland areas in South Korea show thin soil layers on the upper part of the bedrock, but in coastal areas, layers of reclaimed soil are present over bedrock, resulting in a greater depth to the bedrock (Song et al. 2018). When compared with the OK result (Fig. 8b), which is generally used when performing geostatistical interpolation, DEM patterns are reflected in detail using SK-LVM, leading to a reduced smoothing effect and an increased resolution.

\subsubsection{Integration}

The weighted sum is mainly used for data integration in the assessment of risk and vulnerability, and the weight is calculated using a statistical method (Cutter et al. 2003; Siagian et al. 2014; Frigerio et al. 2016) or is subjectively determined through expert surveys (Mohanty et al. 2007; Han and Kim 2019).

Seismic and geotechnical vulnerability indicators were integrated into a single map because they are natural environmental factors with spatial variations. Therefore, a weighted sum was used, while weights were estimated according to the accuracy of the data, resolution, and research purpose. Data integration was performed systematically to reflect the spatial characteristics of the data.

In the seismic vulnerability indicators of PSH and the fault-line density map, uncertainties of the input data, such as referring to the seismic record and active fault location, were relatively large, and thus, only approximate information, such as a tendency, could be obtained (Figs. 2 and 3). On the contrary, the 
results for bedrock depth, which is a geotechnical vulnerability indicator using borehole information as input data, were calculated through an integration process with the DEM using SK-LVM, the resolution of which was relatively high (Fig. 8a). In addition, because we aimed to evaluate vulnerability based on the bedrock depth distribution in the event of an earthquake, the weight ratio between geotechnical and seismic vulnerabilities was set to 2:1. Data standardization was required before performing the weighted sum calculation, and hence, rescaling was applied at all levels prior to integration.

Figure 9 shows a schematic diagram of the integration process of seismic and geotechnical vulnerability. First, weights were assigned according to the degree of detail of the spatial distribution information in PSH and fault-line density. Then, the weighted values were summed with the bedrock depth for integration, as shown in Figure 9.

\subsection{Calculation of social vulnerability index}

The SVI was calculated by applying statistical techniques to the data on vulnerable people, old houses, and road density information. First, the Z-score was applied to standardize the data. Next, to confirm the suitability of principal component analysis (PCA), Kaiser-Mayer-Olkin (KMO) and Bartlett's tests were performed. The KMO measure checks whether correlation between the variables is well explained by other variables. PCA is considered suitable if the KMO result is higher than the reference value of 0.5 . In addition, Bartlett's test shows the suitability of the statistical analysis model. The model suitability is judged to be significant if the significance probability is 0.05 or less (Sharma 1996). After meeting these conditions, PCA was performed. Using the eigenvector of the first principal component, the weight was calculated by dividing the total sum by the eigenvector of each variable (Han et al. 2015). Finally, the weighted values were summed using the calculated weights to calculate the SVI.

\subsection{Seismic risk matrix}

The calculated seismic, geotechnical, and social vulnerabilities had different types and units of data. Therefore, the qualitative characteristics of each map needed to be comparatively evaluated for each administrative district (SafeLand 2012). In this study, raster-type seismic and geotechnical vulnerabilities were averaged for each administrative district, and then these vulnerabilities and SVI were graded based on the same criteria. For each grade, the quantile method was used to apply a common criterion, so that each grade has approximately $20 \%$ of the total number of data. In this case, a higher grade indicates higher vulnerability. Then, a seismic risk matrix was constructed and applied. Reconstruction is allowed according to the characteristics of the research (ISO/DIS 2009). The seismic risk matrix was prepared based on the standardized risk assessment procedure according to the probability of occurrence and consequence proposed by the International Organization for Standardization (ISO) (ISO/IEC 2009).

Figure 10 shows the seismic risk matrix. Seismic and geotechnical vulnerabilities related to probability were placed on the horizontal axis and the related SVI was placed on the vertical axis. In addition, the two vulnerabilities were constructed symmetrically, so that they contributed equally to seismic risk because objective and accurate information is insufficient at this time to determine which of these vulnerabilities 
has a greater impact on risk. The seismic risk map was prepared deterministically with significances, and thus, subdivided into five grades of risk: extreme, high, medium, low, and very low.

\section{Results And Discussion}

\subsection{Seismic and geotechnical vulnerability map}

Histogram-based analysis was performed to determine whether the spatial characteristics of the data were reflected in the seismic and geotechnical vulnerability map, and whether they were properly integrated according to the purpose. Figure 11a-c shows a histogram of PSH, fault-line density, and bedrock depth constructed with spatial information. The PSH pattern showed a smoothed characteristic (Fig. 11a), which was consistent with the spatial distribution characteristics. Figure 11b shows an exponential distribution with a long tail to the right, indicating that the majority of the areas were not affected by fault-line density, but as the presence of a fault is an important parameter in seismic activity, the value has significance even if the frequency was low. However, because the frequency of the minimum value was high, the overall pattern was simple, as most of the regions did not have a fault-line density value (Fig. 3c). Figure 11c shows that the histogram distribution of bedrock depth forms a lognormal distribution, indicating that it contains regional and characteristic information when compared to Figs. 11a and b. Figure 11d shows the histogram distribution of seismic and geotechnical vulnerabilities with the bedrock depth pattern maintained as desired because of integrating the three indicators. Therefore, the integration method used in this study is appropriate.

To verify that each indicator was reflected accurately, the spatial distribution of the seismic and geotechnical (Fig. 12a), PSH (Fig. 2), fault-line density (Fig. 3c), and bedrock depth (Fig. 8a) maps were compared and analyzed. Figure 12a shows a detailed increase and decrease in vulnerability based on bedrock depth distribution information, which was not seen in the PSH and fault-line density maps. This shows a high vulnerability to ground motion amplification when an earthquake occurs at a location with a high bedrock depth. In addition, vulnerability increased in areas with high PSH and fault-line density and vice versa. This pattern was partly due to the small assigned weights, but mainly because of the effect of the strong overall trend in the data.

Overall, the western and southeastern parts of South Korea show higher risk than the northeastern parts. This leads to an L-shaped seismic and geotechnical vulnerability, similar to the PSH distribution. In particular, the region with the highest vulnerability is located in the southeastern part of South Korea, including the city of Gyeongju and Pohang. The northwestern region, including the metropolitan city, Seoul, and the southwestern coastal regions are at a high risk. In the southeastern region, high bedrock depth is distributed in areas where active fault zones with long fault lines are located, showing high vulnerability. In the northwestern region, a high vulnerability is observed in the $\mathrm{N}-\mathrm{S}$ direction because of a high fault-line density distribution in the central part of the region and a high bedrock depth in the southern and western parts of the region. In some areas of the southwestern coast, PSH and fault-line density have little effect, but bedrock depth is high, resulting in a high vulnerability. The northeastern 
region shows a low vulnerability due to low PSH and bedrock depth, even though fault-line density is high. For the assessment of seismic and geotechnical vulnerability, the effects of all three indicators were taken into account. However, the most dominant pattern was based on the distribution of bedrock depth, which is related to earthquake damage, with minor trends of PSH and fault-line density.

Figure $12 \mathrm{~b}$ presents the seismic and geotechnical vulnerability map of the administrative district units in South Korea. As the raster-type map was converted to a vector, the distribution of seismic hazards was simplified, and detailed information was not provided. Therefore, it should be noted that not all regions with high vulnerability exhibit an equally high risk. In addition, the number of administrative districts corresponding to each grade were similar, but the area of each district differed. Therefore, it appears that grade 5 occurred less often in terms of area than other grades. This indicates that cities with a social and industrial development mostly corresponded to grade 5 .

\subsection{Social vulnerability index map}

The KMO test result was 0.601 and the Bartlett's test result showed a significantly low probability, confirming the suitability of the PCA. Table 2 shows the results of the PCA. The eigenvalue of the first principal component was 1.9320 , that is., $>1$, indicating that the first principal component explained the variance of the variables well. The other principal components had eigenvalues $<1$, and the validity of estimating weights by extracting one principal component was examined. The calculated weight value was 0.369 for vulnerable people, 0.343 for the number of old houses, and 0.288 for road density. Therefore, vulnerable people showed the highest statistical significance.

Figure 13 shows the SVI map of South Korea. As the data has no geographic relevance, the map shows a scattered distribution of grades 1-5 compared to the seismic and geotechnical vulnerability map. However, the areas showing a concentration of grades 4-5 are in the southeastern and northwestern regions of South Korea, which is partially consistent with the regions with high seismic and geotechnical vulnerability (Fig. 12b). Therefore, a high seismic risk can be predicted in these administrative districts. The grade 5 vulnerability in the southeastern part is primarily due to the impacts of vulnerable people and old houses (Fig. 5a and b). In the northwest, although there are slight differences in small towns, the three indicators together showed a high vulnerability. The impacts of road density, vulnerable people, and old houses were evident in large metropolitan cities, unlike in small cities (Fig. 5c). The SVI map can be used to comparatively analyze the influence of different indicators in the vulnerable region. Furthermore, highrisk grades were observed in metropolitan cities with high population and building densities and advanced industrialization. This is similar to the characteristics of the seismic and geotechnical vulnerability map. Therefore, large cities will incur large-scale earthquake damages.

\subsection{Seismic risk map}

Figure 14a presents the derived seismic risk map. The map presents five grades: extreme, high, medium, low, and very low, which were classified in the seismic risk matrix. The overall trend indicates that the seismic and geotechnical vulnerability map shows spatial continuity, whereas the social vulnerability 
map shows a scattered distribution. The areas in the southeastern and northwestern part, which were predicted to have a high risk, were mostly classified as extreme grade, although there were some changes in certain areas with the integration of the two maps. In the southeast, regions with seismic and geotechnical vulnerability of grades 4-5 were distributed continuously along the coast. However, social vulnerability showed a sparse distribution of grades $4-5$, and consequently, the extreme grade of seismic risk appeared only in some areas. In the northeastern area, including the Seoul metropolitan area, a longrange distribution with an $\mathrm{N}-\mathrm{S}$ direction of the extreme grade was observed due to seismic and geotechnical vulnerability; social vulnerability appeared in the N-S direction. In the northeast, seismic and geotechnical vulnerability was significantly lower than that in the other regions, but some risks from the effects of social vulnerability were observed. As a result, in both maps, areas with high vulnerability showed high-risk grades and areas with low vulnerabilities showed low-risk grades, with good correlations. The administrative districts with an extreme-risk grade in the seismic risk map also contained regions in which the seismic, geotechnical, and social vulnerabilities were classified as high risk. However, there were also cases in which one vulnerability was moderate and the other was grade 5 , indicating an overall high risk. Therefore, the seismic risk map created in this study indicates that even if a region has low seismic activities and ground motion, if the region has a high risk related to human and social factors, it is vulnerable to large-scale damages. The same principle applies in other cases as well.

Figure 14b shows the instrumental observations of earthquakes in South Korea from August 1978 to May 2018 , reported by the KMA. The southeastern region has an extreme-risk grade as it has experienced earthquakes of $\mathrm{M}_{\mathrm{L}} 5$ or higher. Earthquakes of $\mathrm{M}_{\mathrm{L}} 4$ or higher are shown along the coastal area of the region. Overall, several incidences of earthquakes of $\mathrm{M}_{\mathrm{L}} 3$ or higher can be observed. These observations are consistent with the regions showing extreme and high-risk grades. Earthquake measurements commenced approximately 40 years ago; however, historical earthquake records are important in estimating earthquake damage. Therefore, because the seismic risk grade was historically high in both the southeastern and the northwestern regions, considerable damage and loss are expected in the event of an earthquake in these regions. The northwestern region has recorded only earthquakes of $M_{L} 3$ or lower. However, historically, this region has experienced more than two earthquakes of the modified Mercalli intensity (MMI) scale VIII or higher, with records of houses collapsing and deaths of humans and animals. Multiple instances of earthquakes with MMI VI-VII were recorded through the narration of people who felt the impact of the earthquake and witnessed cracked walls (KMA 2012). Therefore, even a region with a low risk in the seismic risk map should not be interpreted as having no risk, but rather as having a relatively low risk than other regions.

\section{Conclusions}

We conducted a seismic risk analysis of South Korea to assess areas vulnerable to earthquake damages. We considered PSH and fault characteristics to derive the seismic vulnerability indicator, bedrock depth for the geotechnical vulnerability indicator, and vulnerable people, number of old houses, and road density for the social vulnerability indicator. Seismic vulnerability was reflected by bedrock depth. A 
geostatistical technique was applied to show the reliable bedrock depth distribution in the regions. PCA was applied and the weighted values were summed to define the social vulnerability indicator. The seismic and geotechnical vulnerability map and the SVI map were integrated based on the risk matrix. Finally, spatial distributions of the seismic and geotechnical vulnerability map, the SVI map, and the integrated seismic risk map were evaluated.

The analyses of the three maps showed that the southeastern and northwestern parts of South Korea have a similarly high vulnerability in all of them. The southeastern part includes the epicenters of the Gyeongju earthquake that occurred on September 12, 2016 and the Pohang Earthquake on November 15, 2017 , both with $>M_{L} 5$ magnitudes. The northwestern region includes the Seoul metropolitan region, a demographic, economic, and industrial hub. Therefore, these regions are vulnerable to earthquake damage, which can lead to great losses. A comparison of earthquake records with the seismic risk map shows that the seismic risks were high in areas with historical occurrences of large-magnitude earthquakes, indicating the reliability of the results obtained. Therefore, special attention and development of a seismic risk management system is required in regions with high seismic risk.

The seismic risk map in this study was created using spatial analysis of vulnerabilities to earthquake damage. It is possible to identify the regions vulnerable to earthquakes geologically and socially using the map. In addition, the map is expected to serve as a tool providing data for related research and policy planning to reduce seismic risk. The map can be modified and refined by adding other elements and additional data based on the purpose of research. Different results can be achieved depending on the indicators selected. The risk map can help in preparation, response, and mitigation efforts toward earthquake hazard management in South Korea.

\section{Declarations}

Funding This study was supported by the Nuclear Safety Research Program through the Korea Foundation of Nuclear Safety (KoFONS), granted financial resource from the Nuclear Safety and Security Commission (NSSC), Republic of Korea (No. 1705010). This research was also supported by Basic Science Research Program through the National Research Foundation of Korea (NRF) funded by the Ministry of Education (no. 2019R1A6A1A03033167). And This study was also supported by a part of the projected titled "Research on rock properties in deep environment for HLW geological disposal (GP2020002; 21-3115)" funded by the Ministry of Science and ICT, Korea.

Conflicts of interest/Competing interests The authors declare no conflict of interest.

Availability of data and material All of the data sources are open as appearing in Table 1.

Code availability All of the figures were produced by AcrGIS ${ }^{\circledR}$ and MATLAB $®$

Authors' contributions Conceptualization, S.L and S.O.; methodology, S.L and S.O.; writing-original draft preparation, S.L.; writing-review and editing, S.O.; visualization, S.L. 


\section{References}

Brooks N, Adger WN, Kelly PM (2005) The Determinants of Vulnerability and Adaptive Capacity at the National Level and Implications for Adaptation. Global Environment Change 15:151-163.

CAO (2015) Disaster Management in Japan. Japan.

Cutter SL, Boruff BJ, Shirley WL (2003) Social vulnerability to environmental hazards. Social science quarterly 84(2):242-261.

De Magistris FS, d'Onofrio A, Penna A, Puglia R, Silvestri F (2014) Lessons learned from two case histories of seismic microzonation in Italy. Natural hazards 74(3):2005-2035.

Felsenstein D, Lichter M (2014) Social and economic vulnerability of coastal communities to sea-level rise and extreme flooding. Natural hazards 71(1):463-491.

FEMA (2012) Hazus -MH 2.1 Technical Manual. Washington D.C.

Frigerio I, Ventura S, Strigaro D, Mattavelli M, De Amicis M, Mugnano S, Boffi M (2016) A GIS-based approach to identify the spatial variability of social vulnerability to seismic hazard in Italy. Applied Geography 74:12-22.

Goovaerts P. (2000) Geostatistical approaches for incorporating elevation into the spatial interpolation of rainfall. Journal of Hydrology 228(1-2):113-129.

Grasso S, Maugeri M (2009) The road map for seismic risk analysis in a Mediterranean city. Soil Dynamics and Earthquake Engineering 29(6):1034-1045.

Ha GC (2012) A study on vulnerability assessment of compound disasters. Dissertation, University of Seoul.

Han JG, Keon SG, Hong KK (2013) Seismic Analysis of Ground for Seismic Risk Assessment of Architectural Heritage in Seoul. Journal of the Korean Geohynthetics Society 12(4):33-141.

Han JH, Kim JS (2019) A GIS-Based Seismic Vulnerability Mapping and Assessment Using AHP: A Case Study of Gyeongju, Korea. Korean Journal of Remote Sensing 35(2):217-228.

Han SR, Kang NR, Lee CS (2015) Disaster Risk Evaluation for Urban Areas Under Composite Hazard Factors. Journal of the Korean Society of Hazard Mitigation 15(3):33-43.

Han SW (2011) Korean seismic design code and application status. Architectural Institute of Korea 55(5):22-26.

ISO/DIS 31000 (2009) Risk Management-Principles and Guidelines on implementation. 
ISO/IEC 31010 (2009) Risk management - Risk assessment techniques. International Organization for Standardization.

Related Ministries, Korea (2016) Comprehensive countermeasures of earthquake disaster prevention. Korean Governmental Report.

Related Ministries, Korea (2018) Improvement countermeasures of earthquake disaster prevention. Korean Governmental Report.

Kim HJ (2017) The status and trends of domestic seismic technology. KDB monthly bulletin 734:79-108.

Kim HS, Chung CK (2016) Integrated system for site-specific earthquake hazard assessment with geotechnical spatial grid information based on GIS. Natural Hazards 82(2):981-1007.

KMA (2012) Historical Earthquake Records in Korea (2 1904). Korean Governmental Report.

KMA (2017) Report of 9.12 Earthquake Management. Korean Governmental Report.

KMA (2018) Report of Pohang Earthquake Analysis. Korean Governmental Report.

KOSIS (2020) Statistics of Earthquake and tsunami occurrence. KMA. http://kosis.kr/index/index.do. Accessed 18 May 2020.

Kyung JB, Kim MJ, Lee SJ, Kim JK (2016) An Analysis of Probabilistic Seismic Hazard in the Korean Peninsula - Probabilistic Peak Ground Acceleration (PGA). Journal of the Korean Earth Science Society 37(1):52-61.

Lee KH (1988) Earthquakes in Geology of Korea. Kyohaksa, Korea.

Lee KH (1998) Historical earthquake data of Korean. Journal of the Korea Geophysical Society 1(1):3-22.

Lee SY, Oh SH (2019) Assessment of Regional Seismic Vulnerability in South Korea based on Spatial Analysis of Seismic Hazard Information. Economic and Environmental Geology 52(6):573-586.

Mohanty WK, Walling MY, Nath SK, Pal I (2007) First order seismic microzonation of Delhi, India using geographic information system (GIS). Natural Hazards 40(2):245-260.

MOIS (2018) Report on the 2017 Pohang earthquake. Korea.

MPSS (2017) Report on the 9.12 earthquake. Korea.

NEMA (2012) Active fault map and seismic hazard map. Korea.

NEMA (2013) Public Announcement of National Seismic Hazard Map. Korea.

NGII (2017) The National Atlas of Korea 1. JinhanM\&B, Korea. 
NGII (2018) The National Atlas of Korea 3. JinhanM\&B, Korea.

Safeland (2012) Living with landslide risk in Europe: Assessment, effects of global change, and risk management strategies.

Sharma S (1996) Applied multivariate techniques. Wiley, Canada.

Shin DH, Hong SJ, Kim HJ (2016) Investigation on Effective Peak Ground Accelerations Based on the Gyeongju Earthquake Records. Journal of the Earthquake Engineering Society of Korea 20(7):425-434.

Siagian TH, Purhadi P, Suhartono S, Ritonga H (2014) Social vulnerability to natural hazards in Indonesia: driving factors and policy implications. Natural hazards 70(2):1603-1617.

Song YW, Chung CK, Park KH, Kim MG (2018) Assessment of Liquefaction Potential Using Correlation between Shear Wave Velocity and Normalized LPI on Urban Areas of Seoul and Gyeongju. Journal of the Korean Society of Civil Engineers 38(2):357-367.

Sun CG, Chun SH, Ha TG, Chung CK, Kim DS (2008) Development and application of GIS-based tool for earthquake-induced hazard prediction. Computers and Geotechnics 35(3):436-449.

Sun CG, Kim HS (2017) GIS-based regional assessment of seismic site effects considering the spatial uncertainty of site-specific geotechnical characteristics in coastal and inland urban areas. Geomatics, Natural Hazards and Risk, 8(2):1592-1621.

Toprak S, Holzer TL (2003) Liquefaction potential index: field assessment. Journal of Geotechnical and Geoenvironmental Engineering 129(4):315-322.

Westgate KN, O'Keefe P (1976) Some Definitions of Disaster. Disaster Research Unit Occasional Paper No. 4. Dissertation, University of Bradford

\section{Tables}

Table 1 Indicators selected for seismic risk analysis 


\begin{tabular}{|c|c|c|c|}
\hline & Indicator & Variable & Source \\
\hline \multirow[t]{4}{*}{$\begin{array}{l}\text { Seismic } \\
\text { vulnerability }\end{array}$} & $\begin{array}{l}\text { Probabilistic } \\
\text { seismic hazard }\end{array}$ & $\begin{array}{l}\text { Probabilistic seismic hazard map of } 475 \\
\text { years return period }\end{array}$ & $\begin{array}{l}\text { NEMA a), } \\
2013\end{array}$ \\
\hline & \multirow[t]{3}{*}{ Fault } & Active fault & \multirow{2}{*}{$\begin{array}{l}\text { NEMA, } \\
2012\end{array}$} \\
\hline & & Lineament map by grade & \\
\hline & & Fault length & KIGAM b) $^{\text {b) }}$ \\
\hline $\begin{array}{l}\text { Geotechnical } \\
\text { vulnerability }\end{array}$ & Bedrock depth & Weathered rock depth & $\mathrm{KICT}^{\mathrm{c})}$ \\
\hline \multirow{5}{*}{$\begin{array}{l}\text { Social } \\
\text { vulnerability }\end{array}$} & \multirow[t]{3}{*}{ Vulnerable people } & Number of people aged under 4 & \multirow{2}{*}{$\begin{array}{l}\text { KOSTAT d), } \\
2018\end{array}$} \\
\hline & & Number of people aged over 65 & \\
\hline & & Number of severely handicapped people & $\begin{array}{l}\text { MOHW e), } \\
2018\end{array}$ \\
\hline & Old houses & Number of houses over 30 years old & $\begin{array}{l}\text { KOSTAT, } \\
2017\end{array}$ \\
\hline & Road & $\begin{array}{l}\text { Road density by each administrative } \\
\text { district }\end{array}$ & $\begin{array}{l}\text { MOLIT f), } \\
2019\end{array}$ \\
\hline
\end{tabular}

a) National Emergency Management Agency

b) Korea Institute of Geoscience and Mineral Resources (https://mgeo.kigam.re.kr/)

c) Korea Institute of Civil Engineering and Building Technology (https://www.geoinfo.or.kr/)

d) Statistics Korea

e) Ministry of Health and Welfare

f) Ministry of Land, Infrastructure and Transport (http://nodelink.its.go.kr/)

Table 2 Eigenvalues and eigenvectors of principal components for vulnerable people, old houses, and road density

\begin{tabular}{lllll}
\hline & & PC1 & PC2 & PC3 \\
\hline Eigenvalue & & 1.9320 & 0.7208 & 0.3472 \\
\hline Eigenvector & Vulnerable people & 0.6361 & -0.1753 & 0.7514 \\
\cline { 2 - 5 } & Old houses & 0.5910 & -0.5153 & -0.6206 \\
\cline { 2 - 5 } & Road density & 0.4960 & 0.8389 & -0.2242 \\
\hline
\end{tabular}

\section{Figures}




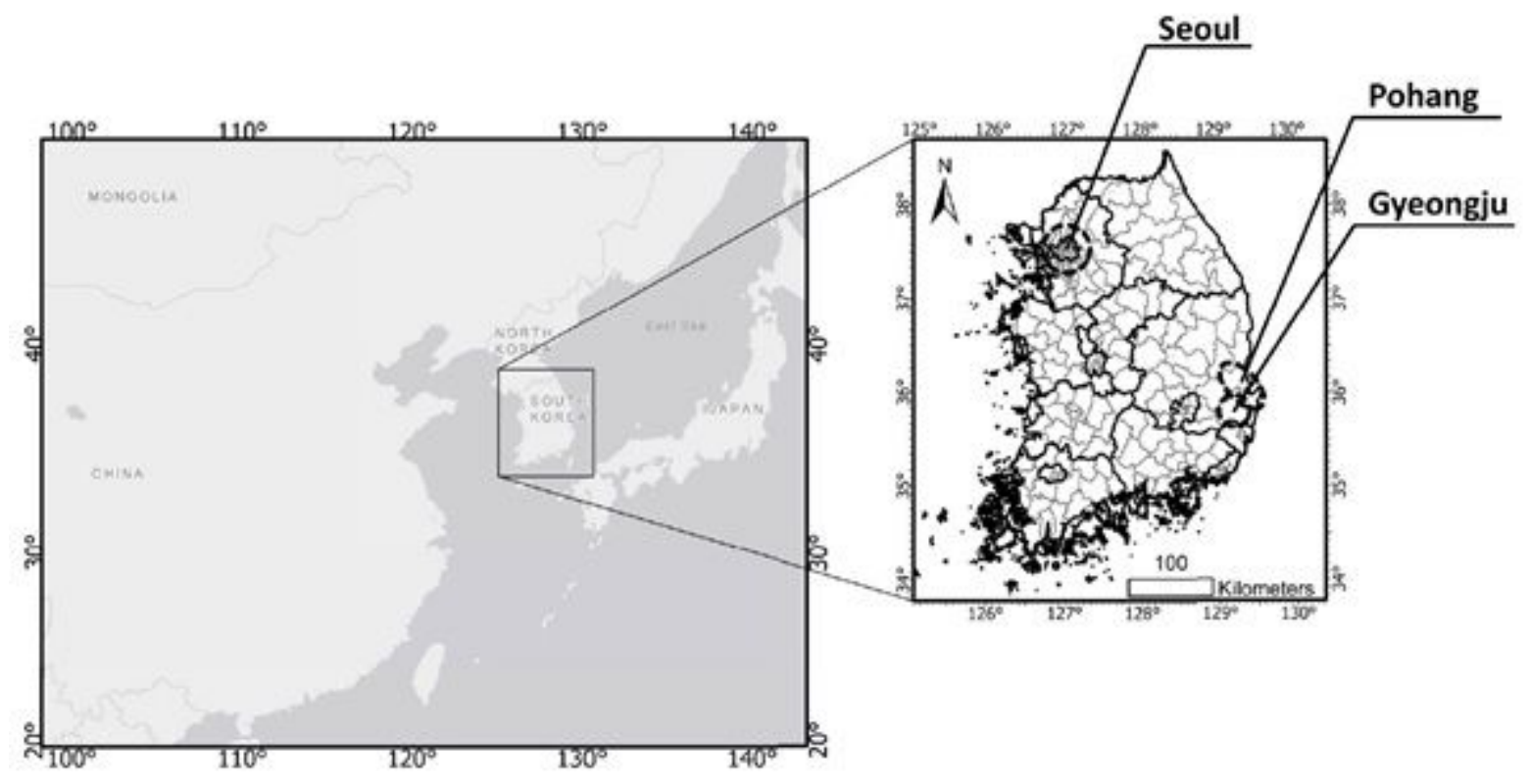

Figure 1

Location of the study area: The geographic location of South Korea is in East Asia. China and Japan are neighboring countries (figure on the left). The study area was limited to South Korea. The black line represents the boundary of administrative districts. The bold black line is the upper administrative district unit in South Korea. The study area covered 247 administrative districts except for some islands, such as Jeju, Ulleungdo, and Dokdo (figure on the right). Note: The designations employed and the presentation of the material on this map do not imply the expression of any opinion whatsoever on the part of Research Square concerning the legal status of any country, territory, city or area or of its authorities, or concerning the delimitation of its frontiers or boundaries. This map has been provided by the authors.

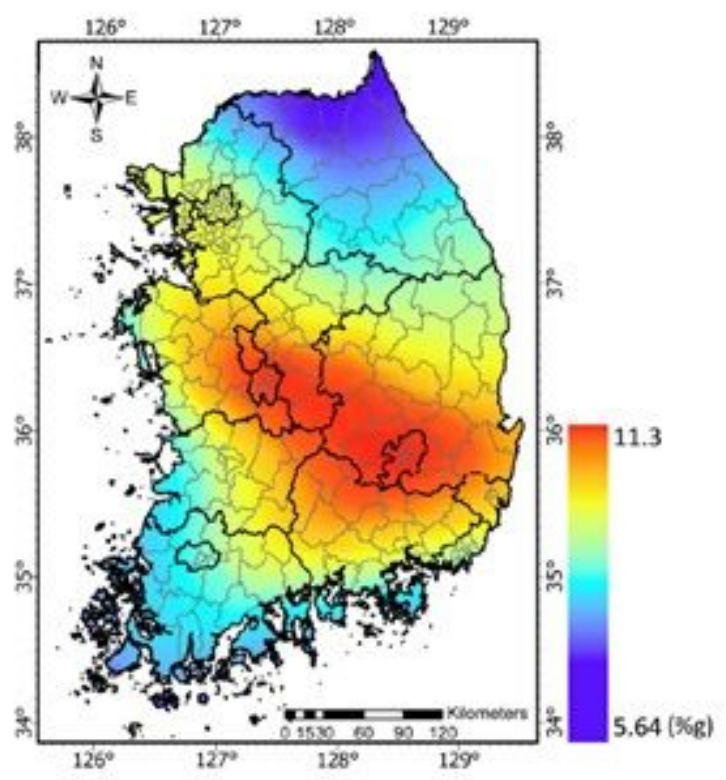

Figure 2 
PSH (unit: \% g) of South Korea (modified after NEMA 2013): High PSH bands show a continuous L-shape distribution from the densely populated metropolitan areas in the northwest to the southeastern region of South Korea. The PSH value is low in regions other than those appearing in the L-shaped region with high $\mathrm{PSH}$. The gray line represents the administrative district boundary. The bold black line represents the upper administrative district unit in South Korea. Note: The designations employed and the presentation of the material on this map do not imply the expression of any opinion whatsoever on the part of Research Square concerning the legal status of any country, territory, city or area or of its authorities, or concerning the delimitation of its frontiers or boundaries. This map has been provided by the authors.

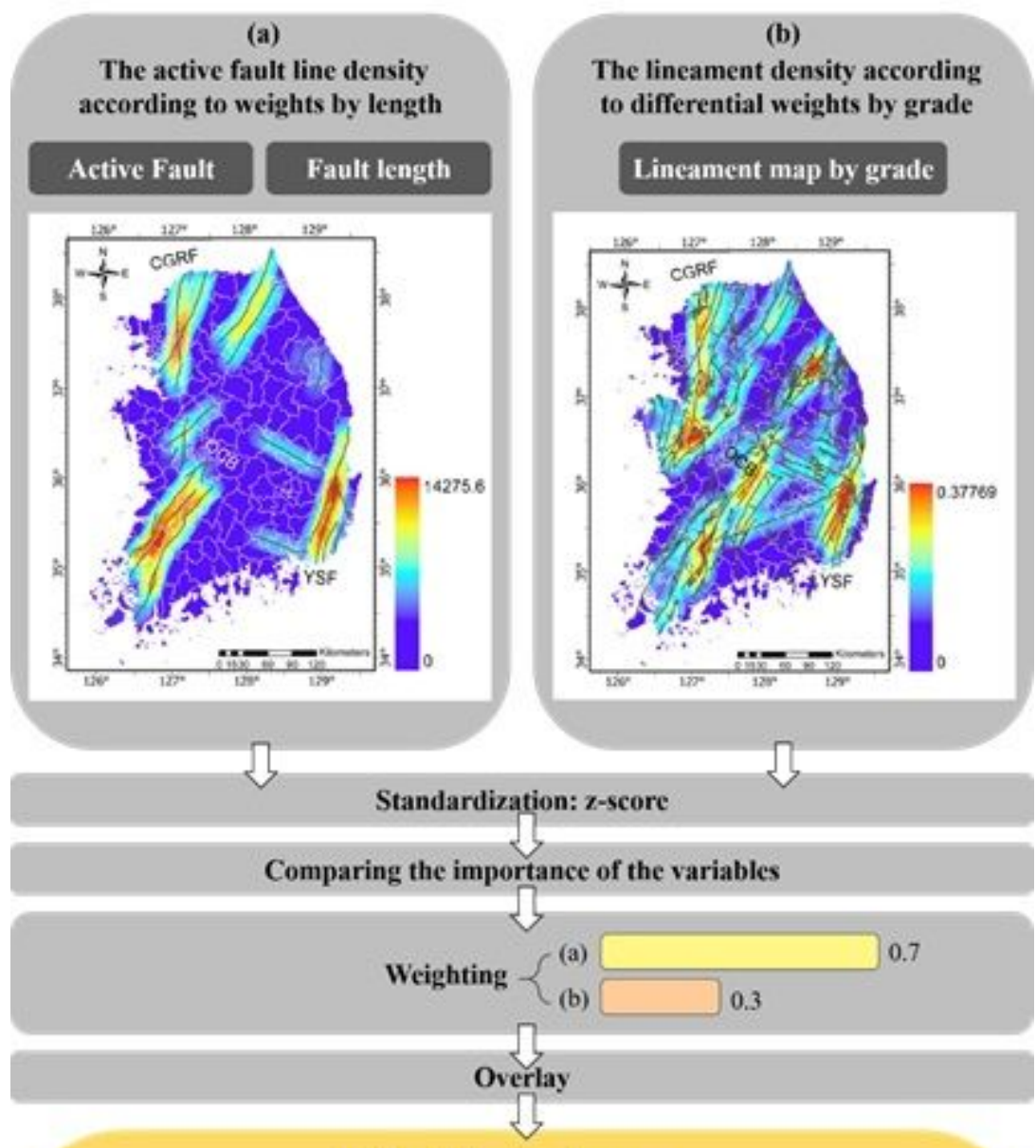

(c) Fault line density map

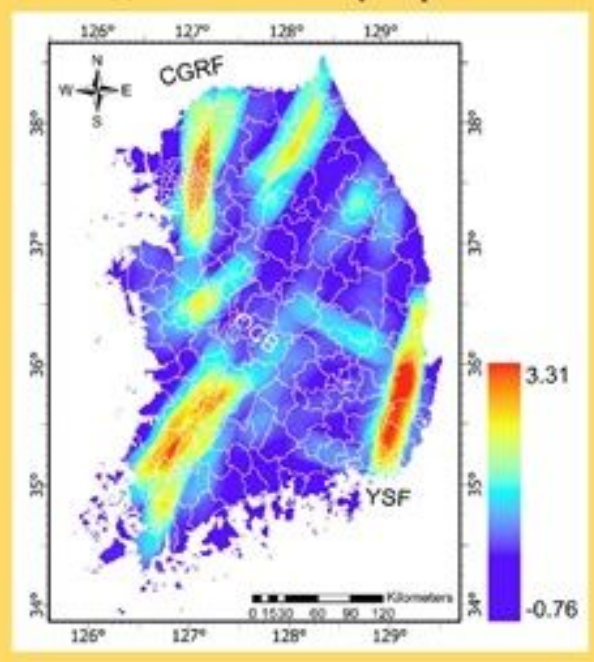




\section{Figure 3}

Schematic of the construction of the fault-line density map: (a) active fault-line density calculated by assigning weights according to the length of the active fault, (b) lineament density calculated by assigning weights according to the class of the lineament, (c) Fault-line density map. The gray lines in (a) and (b) indicate active faults and lineaments, respectively (CGRF: Chugaryeong fault, OCB: part of Ogcheon folded belt, YSF: Yangsan fault). The white lines in all figures represent the administrative district boundaries. Note: The designations employed and the presentation of the material on this map do not imply the expression of any opinion whatsoever on the part of Research Square concerning the legal status of any country, territory, city or area or of its authorities, or concerning the delimitation of its frontiers or boundaries. This map has been provided by the authors.

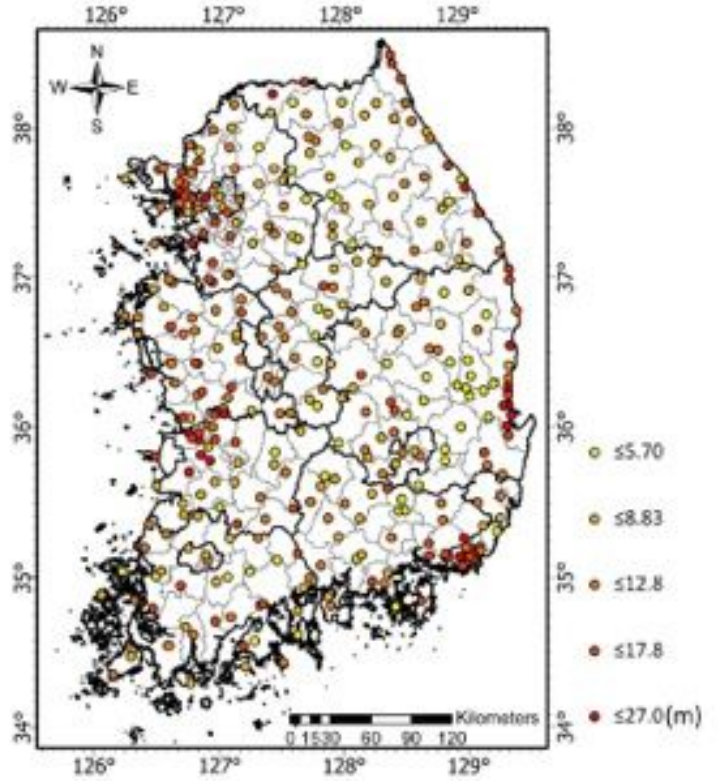

(a)

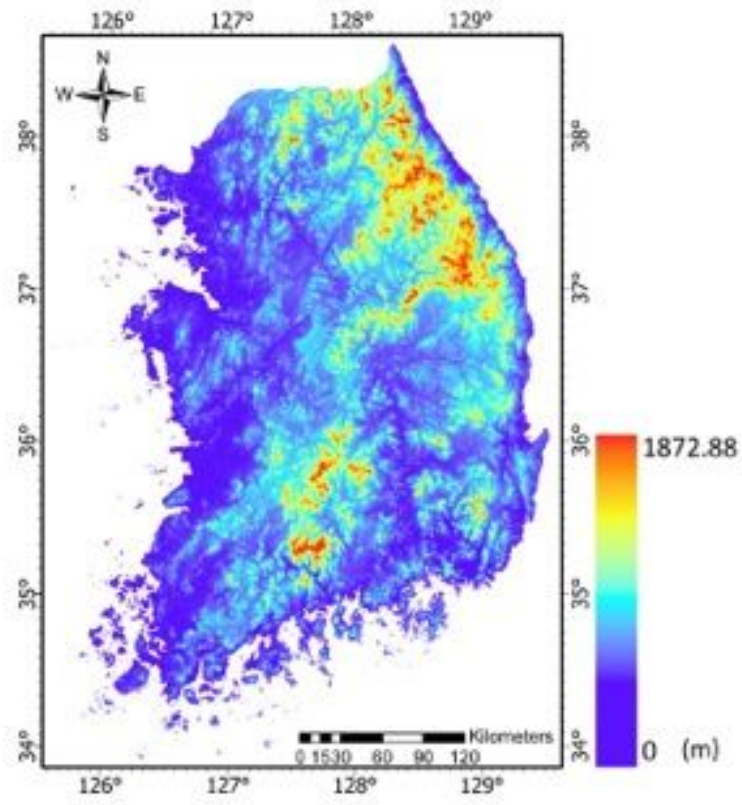

(b)

\section{Figure 4}

(a) Borehole position and bedrock depth (unit: $\mathrm{m}$ ): Going from yellow to red represents a higher bedrock depth. A higher bedrock depth is observed in coastal areas rather than inland and western than eastern regions. (b) DEM (unit: $\mathrm{m}$ ): Going from indigo to red represents a higher elevation. Contrary to bedrock depth, a high elevation is observed in inland areas rather than coastal areas and eastern regions, especially in northeastern regions, compared to western regions. Note: The designations employed and the presentation of the material on this map do not imply the expression of any opinion whatsoever on the part of Research Square concerning the legal status of any country, territory, city or area or of its authorities, or concerning the delimitation of its frontiers or boundaries. This map has been provided by the authors. 


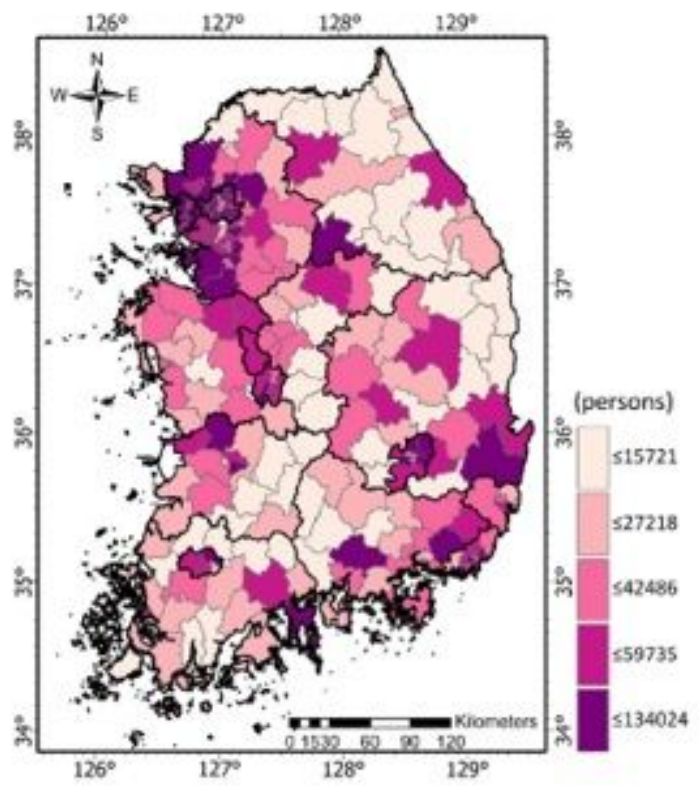

(a)

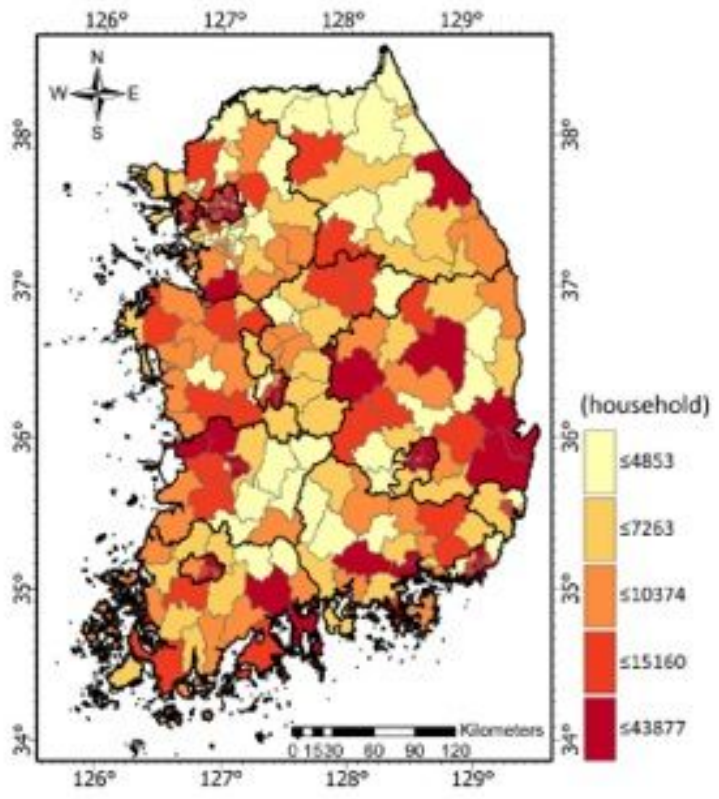

(b)

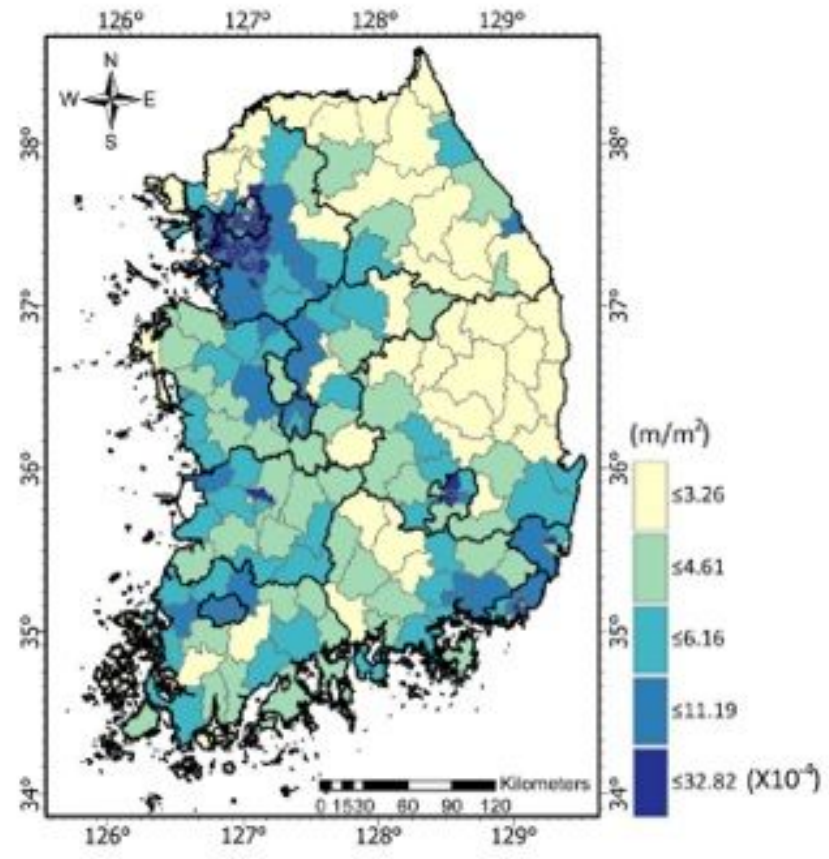

(c)

\section{Figure 5}

Spatial distribution of social vulnerability indicators: (a) vulnerable people (unit: persons), (b) number of old houses over 30 years (unit: household), (c) road density by administrative district (unit: m/m2) Note: The designations employed and the presentation of the material on this map do not imply the expression of any opinion whatsoever on the part of Research Square concerning the legal status of any country, territory, city or area or of its authorities, or concerning the delimitation of its frontiers or boundaries. This map has been provided by the authors. 


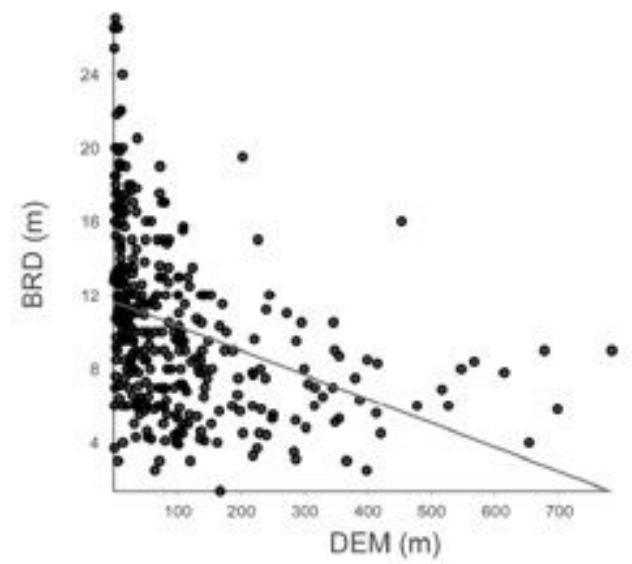

(a)

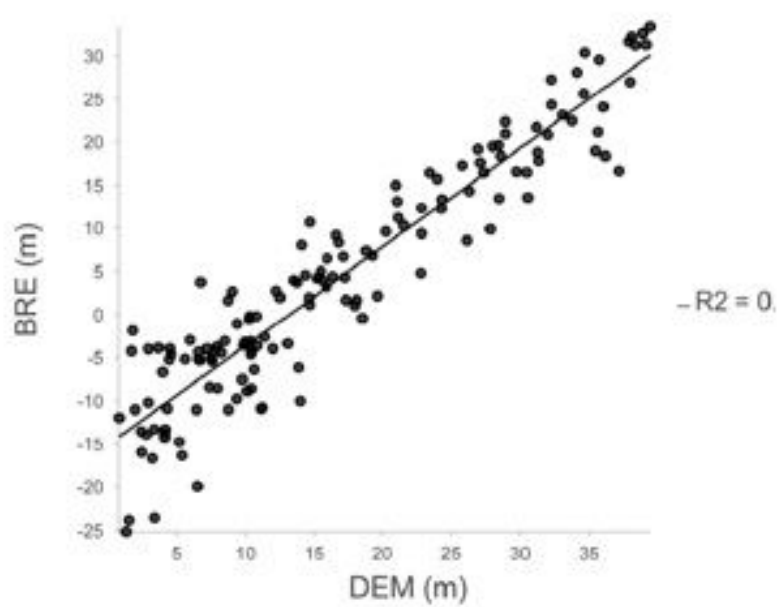

(b)

Figure 6

(a) Scatter plot of bedrock depth (BRD) and all DEM data, (b) Scatter plot of bedrock elevation (BRE) and DEM data below $40 \mathrm{~m}$. 


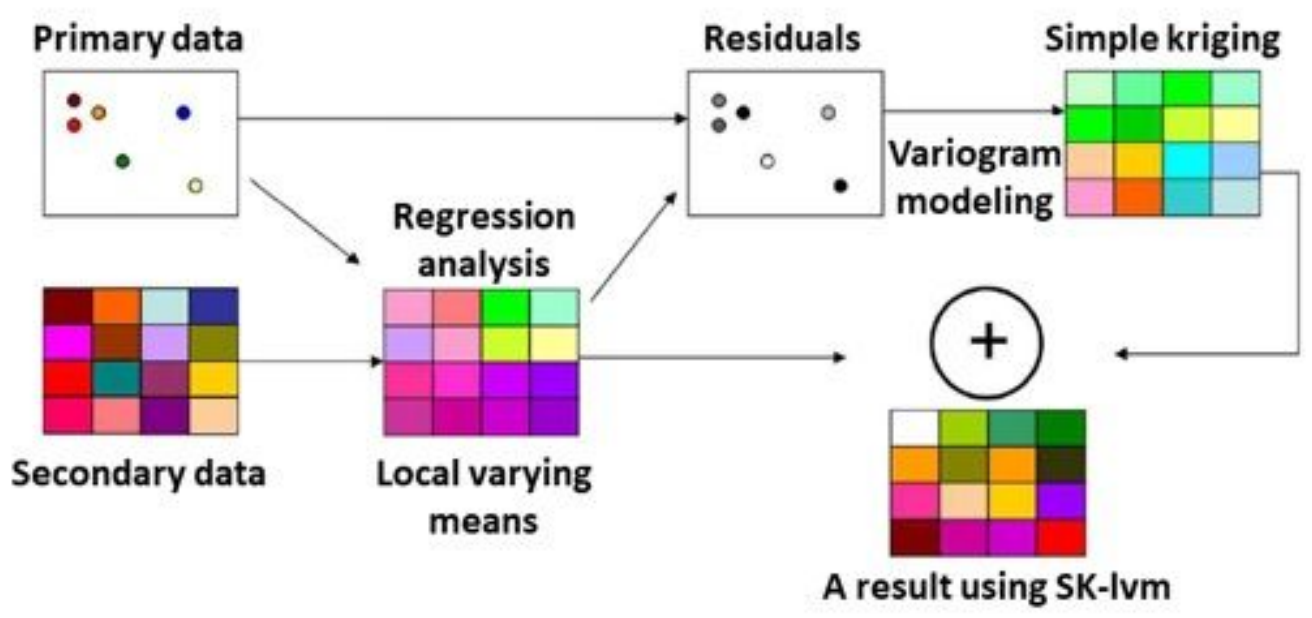

(a)
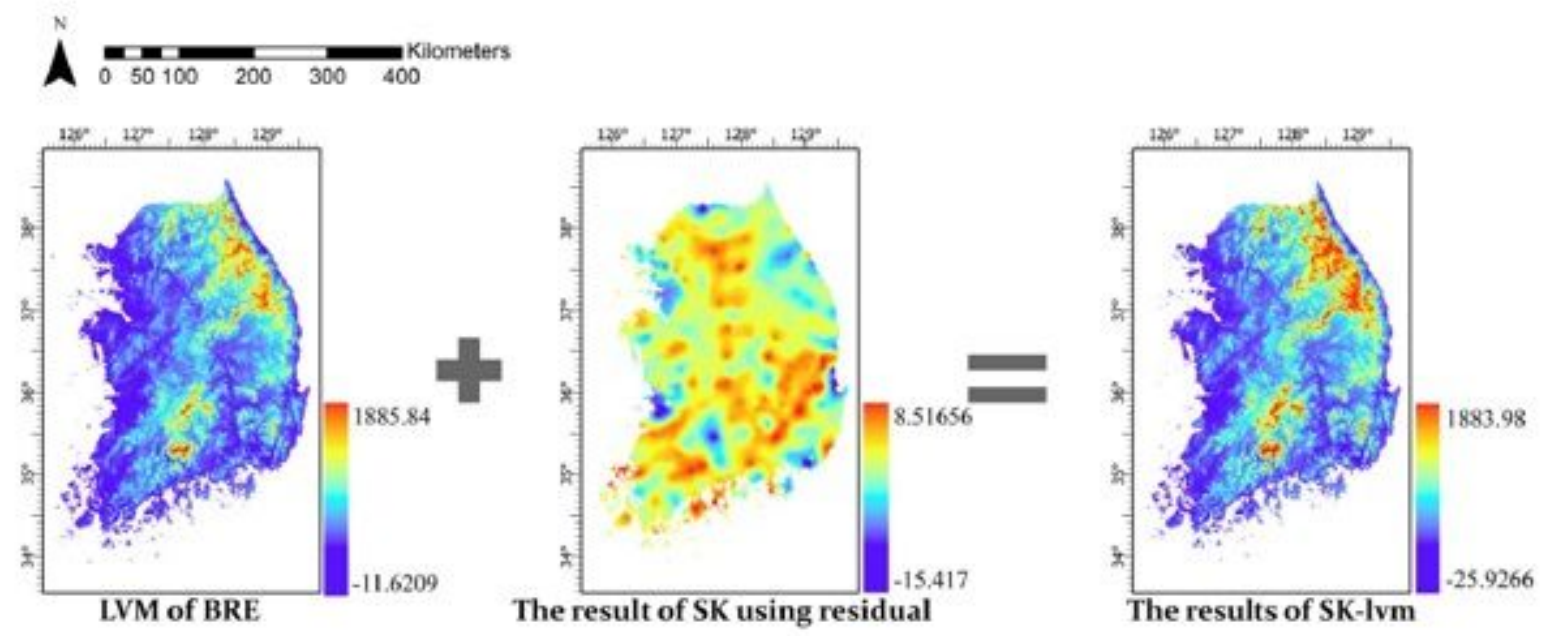

(b)

Figure 7

(a) Schematic of SK-LVM methodology: LVM was calculated via regression analysis of primary and secondary data. The residuals of the calculated LVM and primary data were calculated. Variogram modeling was performed on the residuals; then, SK was performed. Finally, LVM and SK results were summed. (b) Results of BRE estimated using SK-LVM, calculated by adding the LVM of the BRE and the SK results of the residuals. Note: The designations employed and the presentation of the material on this map do not imply the expression of any opinion whatsoever on the part of Research Square concerning the legal status of any country, territory, city or area or of its authorities, or concerning the delimitation of its frontiers or boundaries. This map has been provided by the authors. 


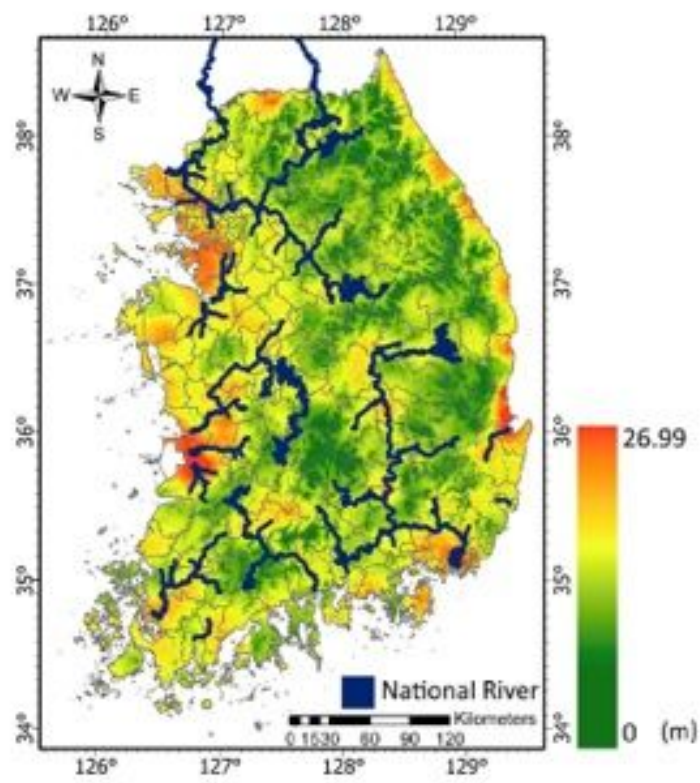

(a)

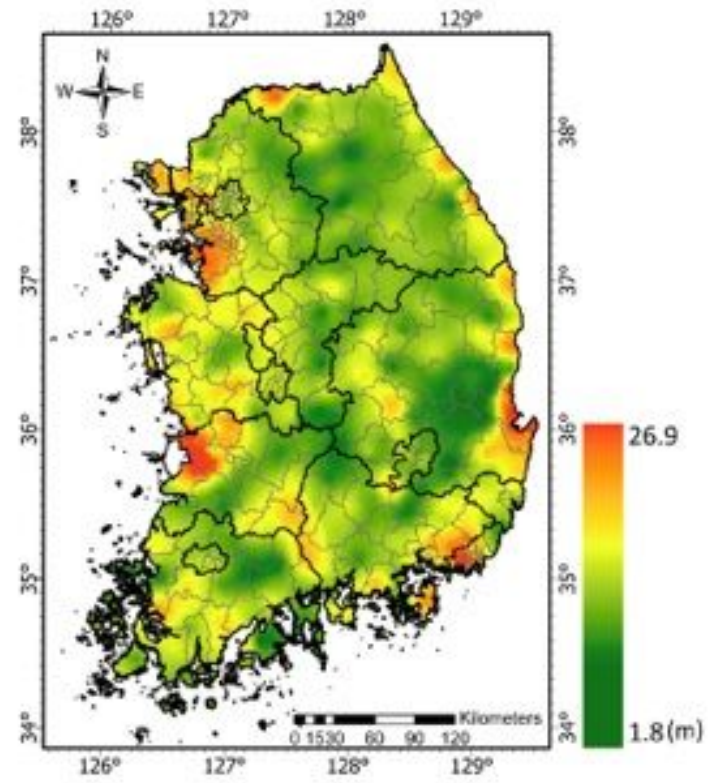

(b)

\section{Figure 8}

(a) Bedrock depth (unit: $\mathrm{m}$ ) estimated using SK-LVM and the location of national rivers in South Korea: The source of the river data is the Han River Flood Control Office (HRFCO). (b) Bedrock depth (unit: $m$ ) estimated using OK: The overall trend was similar to (a), but a smoothing effect appeared. Note: The designations employed and the presentation of the material on this map do not imply the expression of any opinion whatsoever on the part of Research Square concerning the legal status of any country, territory, city or area or of its authorities, or concerning the delimitation of its frontiers or boundaries. This map has been provided by the authors.

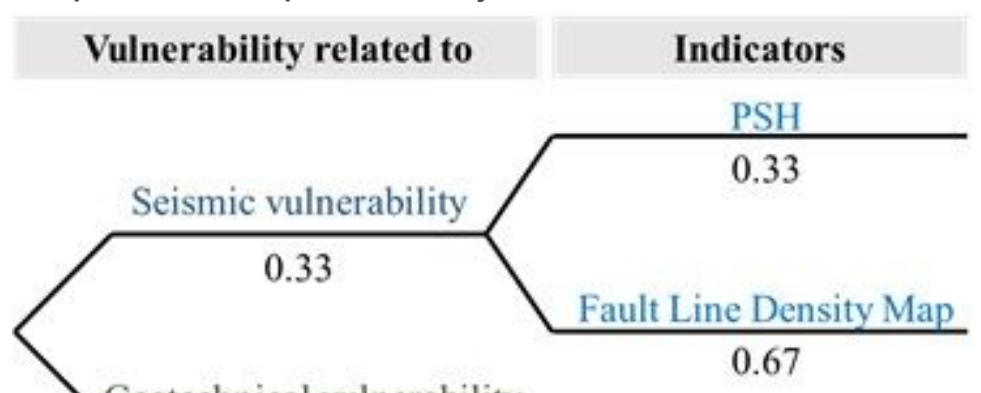

Geotechnical vulnerability

$$
0.67
$$

Bedrock depth

\section{Figure 9}

Schematic of the integration process of seismic and geotechnical vulnerability indicators: The values below each indicator represent the respective weights. Seismic vulnerability was calculated and then 
integrated with bedrock depth, the geotechnical vulnerability indicator.

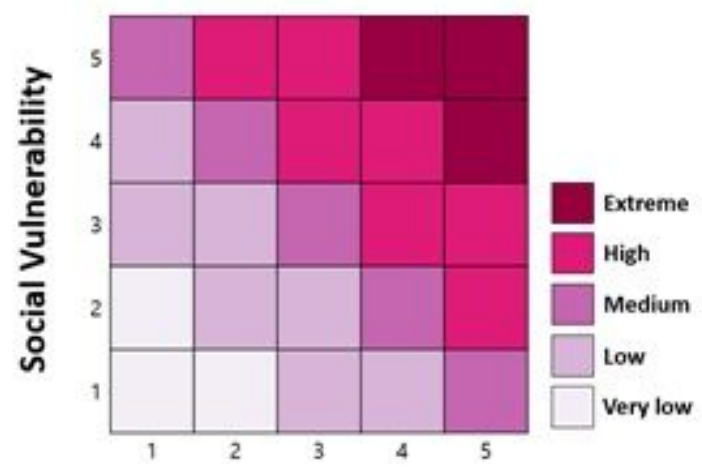

Seismic and Geotechnical Vulnerability

Figure 10

Seismic risk matrix for the integration of seismic, geotechnical, and social vulnerability.

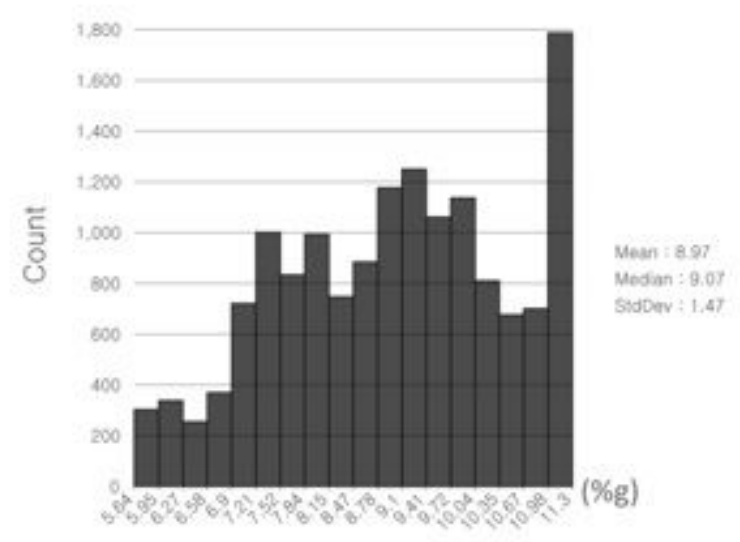

(a)

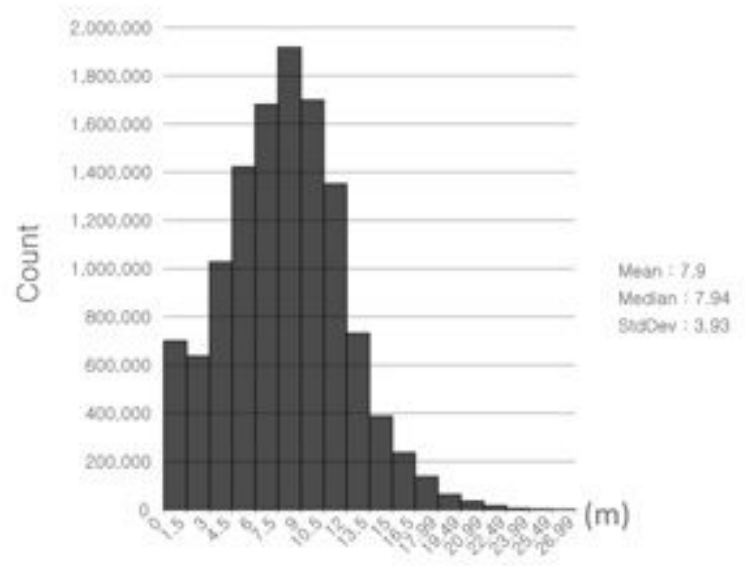

(c)



(b)

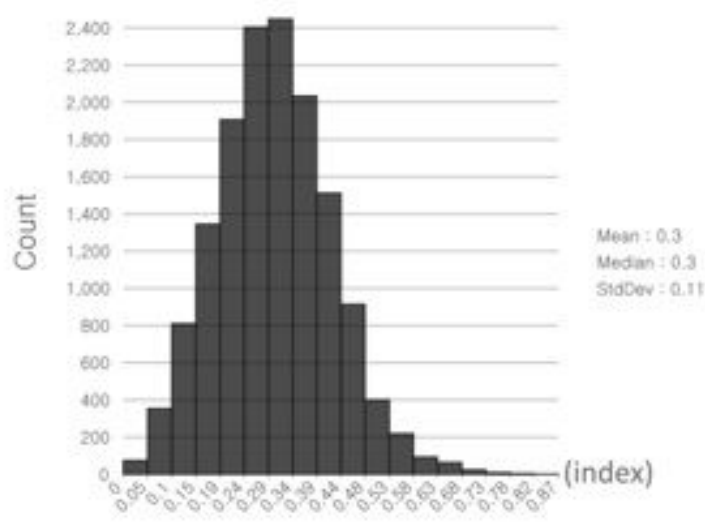

(d)

\section{Figure 11}

11 (a) Histogram of PSH, (b) Histogram of fault-line density, (c) Histogram of BRD, (d) Histogram of seismic and geotechnical vulnerability. 


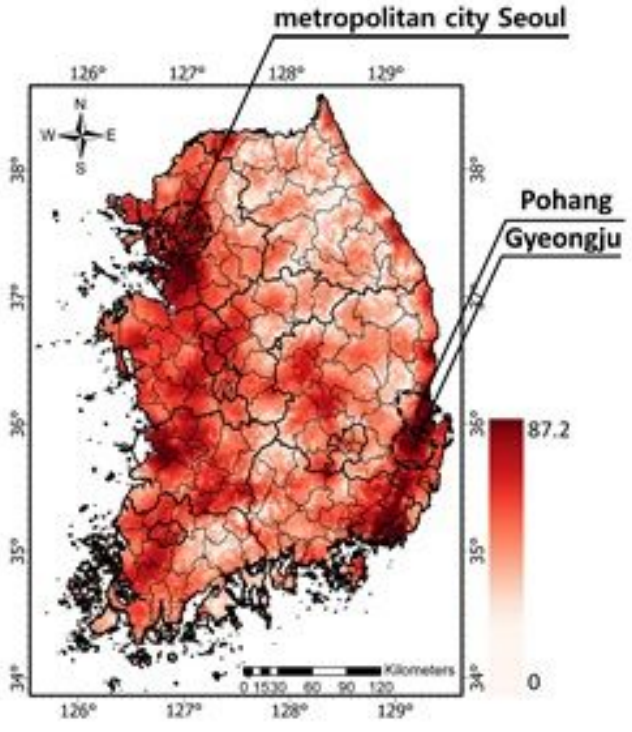

(a)

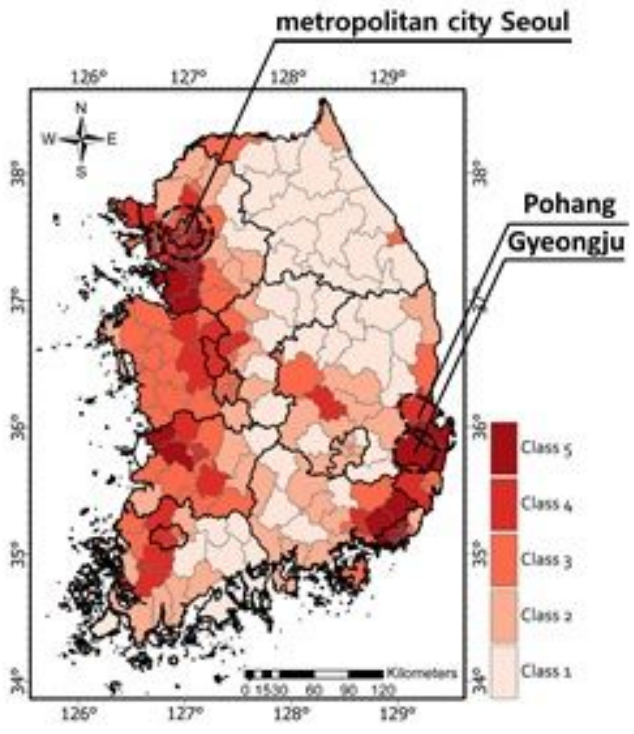

(b)

\section{Figure 12}

(a) Map of seismic and geotechnical vulnerability in raster format, (b) Seismic and geotechnical vulnerability map of administrative district units: (a) and (b) darker colors indicate a higher vulnerability. (b) was obtained by averaging (a) according to administrative district and grading. A high vulnerability occurred in southeastern and northwestern regions. Note: The designations employed and the presentation of the material on this map do not imply the expression of any opinion whatsoever on the part of Research Square concerning the legal status of any country, territory, city or area or of its authorities, or concerning the delimitation of its frontiers or boundaries. This map has been provided by the authors.

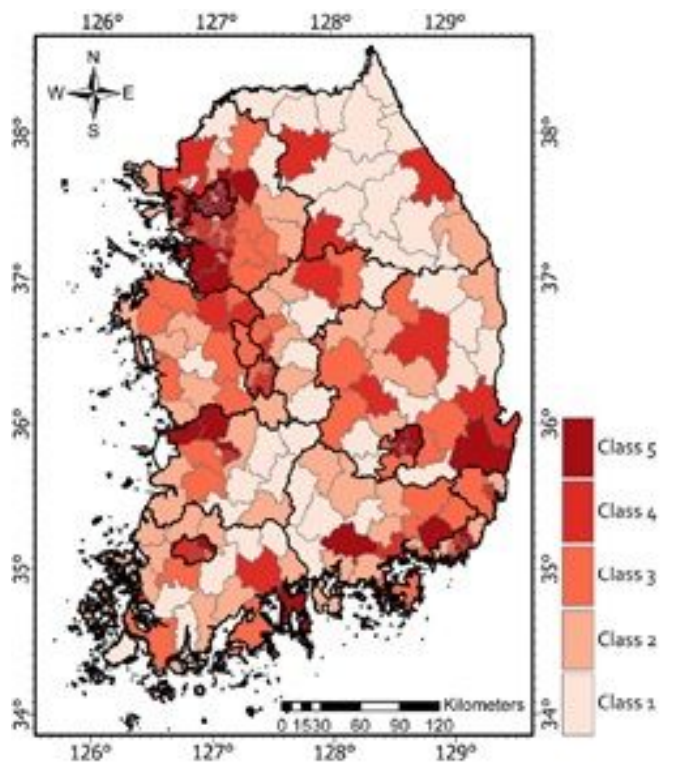

Figure 13 
SVI map: result of the weighted sum of vulnerable people, old houses, and road density information. The darker the red, the higher the vulnerability. Vulnerability increases from small towns to large cities. Areas with concentrations of risk grades 3 or higher are located in the southeastern and northwestern regions. Note: The designations employed and the presentation of the material on this map do not imply the expression of any opinion whatsoever on the part of Research Square concerning the legal status of any country, territory, city or area or of its authorities, or concerning the delimitation of its frontiers or boundaries. This map has been provided by the authors.

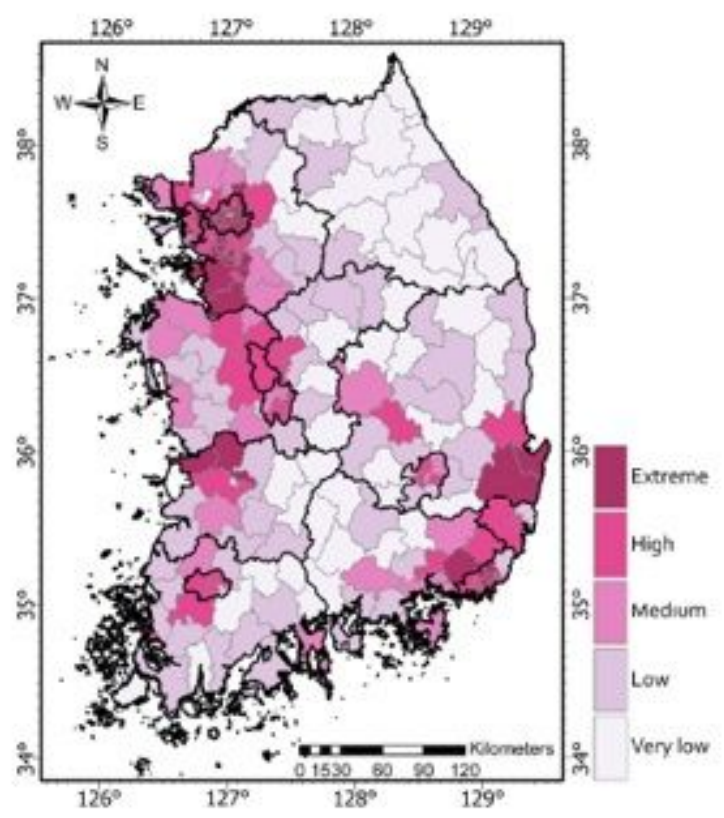

(a)

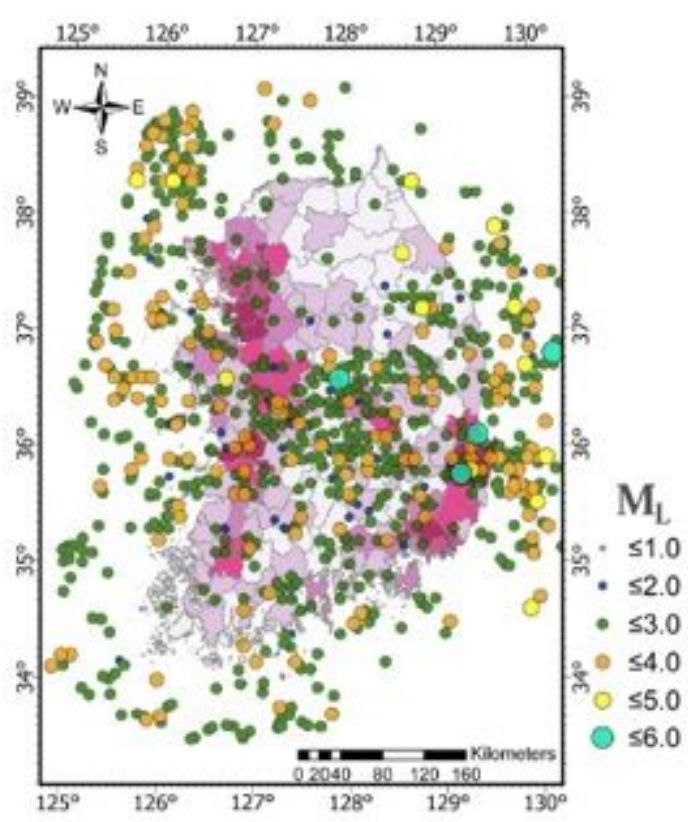

(b)

\section{Figure 14}

(a) Seismic risk map of South Korea: the deeper the purple, the higher the risk. Areas with concentrations of high and extreme grades are located in the southeastern and northwestern regions. (b) Seismic risk map and distribution of instrumentally recorded earthquakes of South Korea: Instrumental earthquake records are from August 1978 to May 2018. Only the locations of the instrumental earthquakes that occurred inland and around inland areas are shown. Larger circle represents a larger magnitude of the earthquake. Note: The designations employed and the presentation of the material on this map do not imply the expression of any opinion whatsoever on the part of Research Square concerning the legal status of any country, territory, city or area or of its authorities, or concerning the delimitation of its frontiers or boundaries. This map has been provided by the authors. 